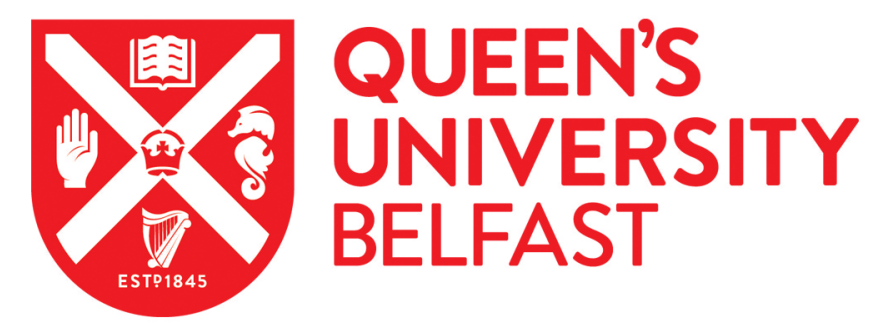

\title{
Factors associated with current and severe physical side-effects after prostate cancer treatment: What men report
}

Steentjes, L., Siesling, S., Drummond, F. J., van Manen, J. G., Sharp, L., \& Gavin, A. (2016). Factors associated with current and severe physical side-effects after prostate cancer treatment: What men report. European Journal of Cancer Care, 27(1), [e12589]. https://doi.org/10.1111/ecc.12589

\section{Published in:}

European Journal of Cancer Care

\section{Document Version:}

Peer reviewed version

Queen's University Belfast - Research Portal:

Link to publication record in Queen's University Belfast Research Portal

\section{Publisher rights}

Copyright 2016 Wiley.

This work is made available online in accordance with the publisher's policies. Please refer to any applicable terms of use of the publisher.

\section{General rights}

Copyright for the publications made accessible via the Queen's University Belfast Research Portal is retained by the author(s) and / or other copyright owners and it is a condition of accessing these publications that users recognise and abide by the legal requirements associated with these rights.

Take down policy

The Research Portal is Queen's institutional repository that provides access to Queen's research output. Every effort has been made to ensure that content in the Research Portal does not infringe any person's rights, or applicable UK laws. If you discover content in the Research Portal that you believe breaches copyright or violates any law, please contact openaccess@qub.ac.uk. 


\section{Factors associated with current and severe physical side-effects after prostate cancer treatment: what men report}

Authors: Laura Steentjes ${ }^{1}$, Sabine Siesling ${ }^{2,3}$, Frances J Drummond ${ }^{3}$, Jeannette G van Manen $^{4}$, Linda Sharp ${ }^{5,6 *}$, Anna Gavin ${ }^{6 *}$

*joint last authors

1. Laura Steentjes, Master of Science. Student Mail address: laurasteentjes@gmail.com

2. Prof Sabine Siesling,PhD, Senior researcher Netherlands Comprehensive Cancer Organisation (IKNL),

3. Professor Outcomes Research and personalised Cancer Care University of Twente Postbus 19079, 3501DB Utrecht, email s.siesling@iknl.nl

3. Frances J Drummond PhD, Postdoctoral research fellow and Principle Investigator, School of Nursing and Midwifery, Department of Epidemiology and Public Health, University College Cork, Cork, Ireland. [mailto:francesjdrummond22@gmail.com]

4. Jeannette G. van Manen, PhD, Assistant Professor, epidemiologist, University of Twente Department Health Technology \& Services Research, Drienerlolaan 5, 7522 NB Enschede, P.O. Box 217

7500 AE Enschede, The Netherlands, P: +31 534893895

Email : j.g.vanmanen@utwente.nl

5. Linda Sharp PhD, Professor of Cancer Epidemiology Newcastle University,

6. Research lead/epidemiologist, National Cancer Registry Ireland (NCRI),

7. Dr Anna Gavin, MB, BCh, BAO, MSC Director, Northern Ireland Cancer Registry (NICR), Queen’s University Belfast, Belfast, Northern Ireland, United Kingdom 


\section{Address of correspondence}

Dr Anna Gavin (a.gavin@qub.ac.uk)

Northern Ireland Cancer Registry

Centre for Public Health - Queens University Belfast

Mulhouse Building

Grosvenor Road

Belfast BT12 6BJ

Northern Ireland, United Kingdom

\section{Word count:}

- $\quad$ Abstract: 196

- $\quad$ Body of text: 4443

- Number of tables: 3 tables, with two on two pages

- $\quad$ Number of figures: 2

\section{Acknowledgements}

The study was funded by grants from the Health Research Board (HRA_HSR/2010/17), Prostate Cancer UK (NI09-03 \& NI-PG13-001) and Northern Ireland R\&D. The RoI National Cancer Control Programme provided additional support. The National Cancer Registry Ireland is funded by the Department of Health and the Northern Ireland Cancer Registry by the Public Health Agency, Northern Ireland. The authors thank the healthcare professionals who facilitated the study; members of Men Against Cancer (MAC) and local cancer support groups who assisted with survey pre-testing; Dr Heather Kinnear for managing the study in NI, Joanne Clooney, Claire O'Callaghan and Audrey Craven-Lynn for survey administration and clerical support; Jenalee Kennedy, Patricia McDowell and Jonathan Mitchell for data entry; Sandra Deady and Colin Fox for providing cancer registration data; registration, data and IT staff in the registries; and, most importantly, the men who participated. We also thank the study Steering Group for advice and input. Finally, we would also like to thank Dr David Donnelly for his help, input and guidance during the process of this study. 


\begin{abstract}
We identified patient and disease characteristics associated with (i) 'current' physical side-effects of any severity and (ii) ' $\geq$ severe’ physical side-effects 'ever' experienced by 3,348 (54\%) prostate cancer (PCa) survivors in Ireland diagnosed 2-18 years previously. Postal questionnaires collected symptoms at diagnosis, post-biopsy complications, comorbidities, primary treatments and physical side-effects post-treatment (urinary incontinence, erectile dysfunction, libido loss, bowel problems, breast changes, hot flushes, and fatigue, 'ever' and 'current' at time of questionnaire completion). Men were grouped by ‘early’ (localised) and 'late' (locally advanced/advanced) disease at diagnosis. Multivariable logistic regression analysis identified patient and disease-related factors associated with post-treatment side-effects. Complications post-biopsy were associated with higher risk of 'current' libido loss and impotence. Radical prostatectomy was associated with higher risk of 'current' and ' $\geq$ severe' incontinence, libido loss and impotence in both early and late disease. In early disease, brachytherapy was associated with lower risk of 'current' fatigue and ' $\geq$ severe' impotence. Comorbidities were associated with higher risk of 'current' experience of four side-effects (incontinence, libido loss, bowel problems, fatigue). Men on active surveillance/watchful-waiting reported lower risk of sexual dysfunction. These findings could inform development of tailored information on side-effects, which, in turn, could inform treatment decision-making and posttreatment monitoring.
\end{abstract}

Keywords: prostate cancer, side-effects, physical effects, decision making process, PiCture study 


\section{Introduction}

Prostate cancer (PCa) is the second most commonly diagnosed cancer among men worldwide and mortality rates have been decreasing in most western countries (Jemal et al., 2010, InternationalAgencyforResearchonCancer, 2012). This, with increased incidence, has resulted in a rise in prevalence (Jemal et al., 2010, InternationalAgencyforResearchonCancer, 2012).

Recommended clinical strategies for early (localised) PCa are radical prostatectomy (RP) or external beam radiotherapy (EBRT). For selected men, brachytherapy (BT), active surveillance (AS) and watchful waiting (WW) are also suitable. AS; for example, can be used for men who may not yet benefit from definitive treatment (Mottet et al., 2015). Appropriate strategies for locally advanced and advanced disease are hormone therapy (HT), EBRT and WW. RP is appropriate for a highly selected group of men with locally advanced disease (Mottet et al., 2015).

While randomised controlled trials of treatment have been conducted, and there is little strong evidence that any of the treatment yield survival benefits over the other (King et al., 2012, Wagner et al., 2011, Heidenreich et al., 2008, Wilt and Ahmed, 2013). PCa treatment decisions are based on the consultation between the patient and the physician, aiming to find the best fit to the patient's personal and clinical characteristics (e.g. disease extent at diagnosis (Talcott et al., 2003, Wagner et al., 2011)). Patient preference should also be considered. All treatments for PCa carry a significant risk of sideeffects and this information may play a role in the treatment decision. In a recent analysis, undertaken by the authors, of 3,348 PCa survivors, at least a two years post-diagnosis, $90 \%$ of men reported 'ever' experienced at least one physical side-effect of treatment. In addition, 75\% of men reported at least one 'current' physical symptom (Gavin et al., 2015). The most common side-effects after PCa treatment are sexual dysfunction (in particular erectile dysfunction and libido loss) urinary incontinence, and bowel problems (Miller et al., 2005, King et al., 2012, Darwish-Yassine et al., 2014, Potosky et al., 2004).

Treatment-related side-effects or symptoms affect the health-related quality of life of PCa patients/survivors (Drummond et al., 2015b). Thus, it would be valuable to identify what factors, if any, are associated with these side-effects. This information could be used to support and inform treatment decision making, help prepare patients for what they can expect after their treatment and also facilitate post-treatment follow-up and monitoring by helping to determine if the patient is likely to need specific support or interventions to alleviate side-effects. Several factors associated with sideeffects have been identified; treatment modality, age, comorbidities, pre-treatment function (e.g. already experiencing urinary incontinence) and the D’Amico risk groups based on Gleason score and Prostate Specific Antigen (PSA) level (Nam et al., 2014, Talcott et al., 2003, Potosky et al., 2004, Sanda et al., 2008, Darwish-Yassine et al., 2014, Chen et al., 2009, Hoffman, 2012, D'Amico et al., 1998). However, the majority of these studies focused on one specific side-effect with most of the 
data limited to urinary incontinence, sexual dysfunction and/or bowel problems and were restricted to the United States or Canada or healthcare system. Little is known about other physical effects, such as hot flushes and fatigue, and their associated factors. Moreover, although, men are more likely to make decisions about treatment based on the possibility of severe, rather than milder side-effects (King et al., 2012), little is known about what factors are associated with either higher or lower risk of experiencing severe side-effects.

Therefore, the aim of this study was to identify patient-related factors and disease-related characteristics associated with a range of current and ever experienced severe, physical side-effects among PCa survivors diagnosed with either early or late disease in a population-based dataset of prostate cancer survivors across two jurisdiction, which operate under different health systems.

\section{Methods}

\section{Survivors}

The study took place in the two countries on the island of Ireland - the Republic of Ireland (RoI) and Northern Ireland (NI). In both countries men were recruited with the same approach; full details are reported elsewhere (Drummond et al., 2015a). In brief, all men diagnosed with invasive PCa, between $1^{\text {st }}$ January 1995 and $31^{\text {st }}$ March 2010, were identified from the National Cancer Registry Ireland (NCRI) in RoI $(n=17,304)$ and the Northern Ireland Cancer Registry (NICR; $n=5,519)$ in November 2011. In both jurisdictions a stratified random sample of $54 \%$ of all survivors $(n=12,322)$ was selected to ensure approximately equal numbers of survivors at $<5$ and $>5$ years post-diagnosis. Survivors were screened for eligibility by health care providers, general practitioners in the RoI and urology clinical nurses in NI. Eligible men had to be: (I) alive, (II) aware of their PCa diagnosis, (III) well enough to complete a survey, (IV) usually a resident of RoI/NI and (V) able to understand English. Subsequently, 6,262 PCa survivors were considered eligible following questionnaire dispatch of whom 3,348 participated by completing the survey, a response rate of $54 \%$.

\section{Survey}

The focus of this study was on men's self-reported physical side-effects after treatment. Two measures of physical side-effects were considered: 'current' side-effects of any severity (i.e. at time of survey completion) and 'severe' side-effects 'ever' experienced (i.e. at any time since diagnosis and treatment for $\mathrm{PCa}$ ). Survivors were asked to provide information about the experience of seven potential treatment-related side-effects: urinary incontinence, erectile dysfunction, libido loss, bowel problems, breast changes, hot flushes, and fatigue. They were asked to indicate whether they had ever experienced each side-effect and, if so, how severe the symptoms were at their worst (from 1 (very mild) up to 5 (very severe)) and whether they were currently experiencing the side-effect. Men were also asked to report all treatments received, including dates of commencement and completion for 
each treatment, and to provide information on their socio-demographic characteristics. Men were asked to indicate whether they had pre-treatment symptoms regarding urinary (increased frequency, pain urinating, blood in urine), bowel (diarrhoea, constipation) and/or sexual (/erectile dysfunction) function. Additionally, they were asked to signify which comorbidities, if any, were present at diagnosis from a list of conditions (heart or lung disease, stroke, diabetes, high blood pressure, diverticular disease, bowel problems (e.g. constipation/diarrhoea), other cancer, depression or other) and, if they had a biopsy, whether they experienced any possibly related complications (bleeding into bladder/rectum and infection).

Surveys were posted to eligible men between April and September 2012. Up to two written reminders at two weekly intervals, with a second copy of the survey in the second reminder, were sent to nonresponders.

\section{Cancer registry data}

For respondents, information on date of diagnosis, stage at diagnosis (TNM classification) and Gleason Grade (GG) was extracted from the cancer registries. The NCRI collected GG as a categorical variable; low (GG 2-4), medium (GG 5-7) or high grade (GG 8-10). Data on survivors in NI, diagnosed in early years, had low completeness of staging therefore supplementary staging information was abstracted from medical records of responders.

\section{Ethical approval}

All procedures were in accordance with the ethical standards of the Irish College of General Practitioners, the Office for Research Ethics Committee NI and with the 1964 Helsinki Declaration and its later amendments. Research governance approval was obtained from the five NI Health Trusts. Informed consent was obtained from all individual participants included in the study through return of completed questionnaires and/or consent forms

\section{Statistical analysis}

Respondents were grouped into localised disease and locally advanced/advanced disease for analysis. Localised disease consisted of survivors with stage I/II and GG 2-7 at diagnosis, labelled as early disease $(n=1,700)$. Locally advanced/advanced disease survivors had stage III/IV and any GG at diagnosis, labelled as late disease $(n=689)$. Survivors with other combinations of stage and $G G$, or unknown stage or GG, were excluded from analysis ( $\mathrm{n}=959)$ leaving 2,389 PCa survivors for analysis.

Outcome variables were the seven physical side-effects investigated. Separate analyses were conducted for side-effects experienced currently and severe side-effects ever experienced. Potential explanatory variables were; age at diagnosis $(<59 / 60-69 / \geq 70$ years), comorbidities at diagnosis (none/1-2/ $\geq 3$ ), highest level of education completed (primary/secondary/ $\geq$ tertiary), jurisdiction 
(RoI/NI), living alone (living alone/living with others), time since diagnosis (2-5/5-10/>10 years)), pre-treatment function (urinating more frequently, pain while urinating, blood in urine, erectile dysfunction, loss of interest in sex and back pain (all no/yes)), complications after biopsy (bleeding into bladder/rectum/infection (no biopsy/yes/no), TURPs, no complications after biopsy (no biopsy/yes/no) and treatment 'ever' had (RP, EBRT, HT, BT, AS/WW). HT was coded as having the treatment 'previously', 'currently' and 'never'; other treatments were coded as received 'yes' or 'no'.

Univariate and multivariate analyses were performed in the form of logistic regression to identify factors associated with (i) 'current' side-effects of any severity and (ii) 'severe side-effects ever experienced'. Analyses were weighted by age at diagnosis, jurisdiction, and time since diagnosis to assure representativeness for all PCa survivors in Ireland. A severe side-effect was defined as one that the survivor reported as severe or very severe at its worst. Multivariate analysis was performed initially including all variables which had a p-value of $\leq 0.10$ in univariate analysis. Subsequently, backward selection was used to build the multivariate models with the p-value of $\leq 0.05$ used as the criterion to include the variable in the model. Correlation between the variables included in the model was also assessed to ensure that collinearity was not an issue with the final models. Model goodnessof-fit of the different models were investigated with help of the Nagelkerke $\mathrm{R}^{2}$ and the HosmerLemeshow test. Missing data in explanatory variables were handled with a fully conditional specification multiple imputation method with five imputations and weighted for all PCa survivors in the population $(n=22,823)$. Missing data in outcome variables were coded as 'never had the sideeffect'.

In addition, sensitivity analysis was performed for two 'current' side-effects (urinary incontinence and erectile dysfunction) and early and late disease to explore the impact of the imputation of missing data. This was addressed by comparing the factors associated with the side-effect in the original dataset with those obtained in analysis of the pooled dataset generated by the multiple imputation method keeping the rest constant. The statistical analysis was carried out in SPSS version 20.

\section{Results}

Survivors

Characteristics of the survivors and differences between early disease and late disease are shown in table 1. Time since diagnosis, age at diagnosis, living alone, and highest educational level achieved were equally distributed in early and late disease groups. In terms of treatment, HT (early: 33\% vs. late: $66 \%$ ) and EBRT (53\% vs. 70\%) were more common in the late disease group and BT (7\% vs. $2 \%$ ) and AS/WW (6\% vs. 1\%) were more common in the early disease group. Reasons for nonparticipation were administrative issues, queries regarding questionnaire content, being unaware of their prostate cancer diagnosis or having data protection issues (Drummond et al., 2015a). 


\section{Prevalence of side-effects}

Prevalence of side-effects are shown in figure 1a (early disease) and 1b (late disease). The prevalence of both 'current' and 'severe side-effects ever experienced' were higher in the late disease group. For 'current' side-effects, the greatest difference were in; loss of libido (early: $42.4 \%$ vs. late: 57.0\%), hot flushes (8.8\% early vs. $27.9 \%$ late) and fatigue (18.8\% early vs. $30.5 \%$ late). The biggest differences in the occurrence of 'severe' side-effects between those with early and late disease were loss of libido ( $25.8 \%$ early vs. $41.0 \%$ late), impotence (39.6\% early vs. $52.7 \%$ late) and fatigue ( $16.1 \%$ early vs. $29.1 \%$ late).

\section{Factors associated with 'current' side-effects in early disease}

Factors significantly associated in multivariate analyses with 'current' physical side-effects in early disease are presented in table 2. Living with others was associated with a higher risk of 'current' loss of libido (multivariate OR=1.56; 95\% CI 1.13-2.11) and impotence (1.39; 1.01-1.91). Higher education was associated with a higher risk of erectile dysfunction and associated with a lower risk of hot flushes and fatigue. Being $\geq 10$ years post-diagnosis was associated with a lower risk of fatigue $(0.55 ; 0.35-0.85)$ and being $5-10$ years post-diagnosis was associated with a lower risk of hot flushes (0.60; 0.39-0.92). Living in NI was associated with higher risk of loss of libido, bowel problems and fatigue.

Treatments were associated with a higher risk of 'current' side-effects. RP was associated with a higher risk of urinary incontinence (3.03; 2.28-4.03), loss of libido $(1.72 ; 1.33-2.22)$ and erectile dysfunction (3.30; 2.56-4.23). EBRT was associated with a higher risk of bowel problems (3.35; 2.384.71) and hot flushes (1.93; 1.15-3.22). Any HT (previously and currently) was associated with a higher risk of loss of libido, breast changes and hot flushes while currently receiving HT was associated with a higher risk of fatigue $(2.16 ; 1.44-3.26)$. BT was associated with a lower risk of fatigue (0.46; 0.24-0.89). AS/WW was associated with a lower risk of urinary incontinence (0.40; 0.16-0.99), loss of libido (0.37; 0.21-0.65), impotence $(0.21 ; 0.12-0.34)$ and fatigue $(0.16 ; 0.05-0.46)$.

Health at diagnosis was associated with a risk of 'current' side-effects. Urinating more frequently was associated with urinary incontinence $(1.72 ; 1.25-2.35)$, bowel problems $(1.48 ; 1.08-2.02)$ and fatigue $(1.45 ; 1.09-1.92)$. Loss of interest in sex was associated with a higher risk of loss of libido (1.79; 1.262.55). Post treatment erectile dysfunction was associated with a higher risk of post treatment loss of libido and erectile dysfunction. Back pain was associated with a higher risk of fatigue $(1.78 ; 1.24-$ 2.57). Multiple $(>3)$ comorbidities at diagnosis was associated with a higher risk of urinary incontinence (2.34; 1.34-4.09), loss of libido (1.68; 1.03-2.75), bowel problems (3.29; 1.88-5.76) and fatigue $(2.07 ; 1.21-3.53)$. Complications post-biopsy, in particular bleeding into the bladder, was associated with a higher risk of bowel problems (2.32; 1.08-4.96). Bleeding into the rectum was 
associated with a higher risk of breast changes (5.19; 1.76-15.29). Experiencing complications postbiopsy was associated with a higher risk of impotence $(1.72 ; 1.17-2.54)$ and loss of libido $(1.55 ; 1.05$ 2.31).

Factors associated with 'severe side-effects ever experienced' in early disease

Table 2 shows the factors significantly associated, in multivariate analyses, with ever experiencing severe side-effects in early disease. Older age at diagnosis, especially being $\geq 70$ years, was associated with a lower risk of loss of libido (0.48; 0.33-0.68) and impotence $(0.71 ; 0.51-1.00)$. Higher education was associated with a higher risk of impotence and lower risk of hot flushes and fatigue. Being $\geq 10$ years or more post-diagnosis was associated with a lower risk of fatigue (0.48; 0.28-0.82). Living in NI was associated with a higher risk of loss of libido, hot flushes and fatigue.

RP was associated with a higher risk of urinary incontinence, loss of libido, impotence, hot flushes and fatigue. EBRT was associated with a higher risk of bowel problems, hot flushes and fatigue. Previous and current HT was associated with a higher risk of loss of libido, breast changes, hot flushes and fatigue. BT was associated with a lower risk of impotence. AS/WW was associated with a lower risk of loss of libido and impotence.

Loss of interest in sex pre-treatment was associated with a higher risk of loss of libido $(2.00$; $1.43-$ 2.78). Pre-treatment erectile dysfunction was associated with a higher risk of erectile dysfunction (1.62; 1.19-2.20). Back pain was associated with a higher risk of hot flushes (1.72; 1.02-2.89) and fatigue (1.53; 1.13-2.08). Presence of multiple comorbidities at diagnosis was only associated with a higher risk of bowel problems (2.80; 1.22-6.43). Complications post-biopsy, especially bleeding into the bladder, was associated with a higher risk of impotence (2.25; 1.33-3.81).

\section{Factors associated with 'current' side-effects in late disease}

Table 3 indicates the factors which were significantly associated, in multivariate analyses, with 'current' side-effects in late disease PCa. Older age at diagnosis, was associated with a lower risk of impotence, hot flushes and fatigue. Living with others and higher education were associated with a higher risk of impotence. Being $>5$ years post-diagnosis was associated with a lower risk of hot flushes and fatigue. Living in NI was associated with a higher risk of loss of libido, breast changes, hot flushes and fatigue.

RP was associated with a higher risk of urinary incontinence (4.45; 2.97-6.66) and erectile dysfunction (1.89; 1.18-3.04). EBRT was associated with a higher risk of bowel problems (2.66; 1.504.73) and breast changes (2.06; 1.13-3.78). Any HT was associated with a higher risk of loss of libido, bowel problems, breast changes and hot flushes. Currently receiving HT was associated with a higher 
risk of fatigue (2.33; 1.36-3.99). AS/WW was associated with a lower risk of erectile dysfunction (0.03; 0.00-0.62).

Urinating more frequently $(1.66 ; 1.14-2.40)$ and back pain $(1.76 ; 1.16-2.67)$ pre-treatment were associated with a higher risk of fatigue. Pre-treatment erectile dysfunction was associated with a higher risk of loss of libido (2.02; 1.36-3.01)) and erectile dysfunction (1.87; 1.19-2.96). Having comorbidities at diagnosis was associated with a higher risk of urinary incontinence, bowel problems and fatigue. Bleeding into the rectum post-biopsy was associated with loss of libido (2.48; 1.06-5.83). Infection post-biopsy was associated with a higher risk of breast changes (3.17; 1.06-9.49). Having complications post-biopsy (not further defined) was also associated with a higher risk of erectile dysfunction $(1.87 ; 1.10-3.18)$.

Factors associated with 'severe side-effects ever experienced' in late disease

Factors significantly associated in multivariate analyses with 'severe side-effects ever experienced' are shown in Table 3. Older age at diagnosis was associated with a lower risk of erectile dysfunction, breast changes, hot flushes, fatigue and loss of libido. Living with others and a higher level of education were associated with higher risk of impotence. Living in NI was associated with a higher risk of loss of libido, erectile dysfunction, hot flushes and fatigue.

RP was associated with higher risk of urinary incontinence $(4.47 ; 2.60-7.67)$ and erectile dysfunction (3.70; 2.15-6.36). EBRT was associated with a higher risk of bowel problems (5.46; 2.09-14.32). Any HT was associated with higher risk of loss of libido, hot flushes and fatigue. Previously receiving HT was associated with a higher risk of erectile dysfunction $(1.81 ; 1.02-3.20)$.

Pre-treatment erectile dysfunction was associated with a higher risk of loss of libido $(1.97 ; 1.36-2.84)$. Multiple comorbidities at diagnosis were associated with a higher risk of fatigue and bowel problems. Bleeding into the rectum post-biopsy was associated with hot flushes (3.02; 1.16-7.88) and fatigue (2.67; 1.12-6.36). Having complications post-biopsy (not further defined) was also associated with a higher risk of urinary incontinence (10.98; 1.04-115.53).

\section{Sensitivity analysis}

There were no changes in the factors that were significantly associated with urinary incontinence between the original and pooled datasets (data not shown). For erectile dysfunction, modest differences were seen for the variable living alone in early disease; and variables AS/WW, living alone, education, no complications after biopsy and age at diagnosis in late disease. These differences related to the significance level of these variables; the odds ratio changed little (data not shown).

\section{Discussion}


This study was performed to provide information that could better inform treatment decision making of patients with both early (localised) and late (locally advanced/advanced) PCa and their clinicians.

We found that treatment was the strongest factor associated with both 'current' and 'severe' physical side-effects in both early and late disease, which is consistent with other studies (Potosky et al., 2004, Darwish-Yassine et al., 2014, Nam et al., 2014, Sanda et al., 2008). In particular, RP was associated with a higher risk for side-effects in early disease; associations were strong for 'current' side-effects and even more pronounced for 'severe' side-effects. In contrast, our results suggest that AS/WW may be associated with a lower risk of physical side-effects. Thus, more widespread use of AS/WW (which was only received by $5 \%$ of men in this study) among suitable men with localised PCa could provide an opportunity to avoid, minimise or delay physical side-effects. This strategy might be of particular interest to those men anxious to avoid incontinence and impotence (Chapple et al., 2002). BT was associated with a lower risk of 'current' fatigue and 'severe' erectile dysfunction. Consistent with this, in another small study BT was found to be the treatment with the highest probability of maintaining erectile function (Robinson et al., 2002). The men who underwent BT in our study were a small and highly select group (mostly resident in RoI and treated privately). Nonetheless, it is an important finding and more research should be done to determine if these results can be replicated in populations where BT is more widely available. Treatments, which were not included in the model could be regarded as unimportant with respect to the predictive value of a side-effect.

Our findings suggest that, in terms of patient-related factors, being younger at diagnosis is more frequently associated with physical side-effects in late disease and with 'severe' physical side-effects. Men $\geq 70$ years were less likely to report physical side-effects ('current' and 'severe') compared to younger men $(<59)$. This could be explained by the fact that younger men are more likely to present without symptoms and via PSA testing. They are more likely to have early disease and with less comorbidities, therefore more likely to have RP with all its known side effects and less likely to be in the WW group. An alternative explanation could be that older men have a different view of life than younger men and may perceive some 'side-effects' to be due to ageing instead of treatment (Korfage et al., 2006). Living with others was associated with a higher risk of sexual dysfunction (erectile dysfunction and loss of libido). This could be due to the fact that most men living with others likely live with a partner and may be more likely to be - or want to be - sexually active, and therefore more alert to sexual problems. For both 'current' and 'severe' physical side-effects, men with tertiary or higher education were less likely to have hot flushes and fatigue - after adjusting for treatment - than men with primary education. This could be a because higher education is a marker for other socioeconomic factors or the fact that less well educated men may have poorer health literacy and know less about options to alleviate side-effects (Knight et al., 2007). Men with higher education are more likely to present for PSA testing, and to be diagnosed with earlier stage disease (Nordstrom et al., 2016). 
Pre-treatment function had an impact on risk of experiencing physical side-effects after treatment; in most cases men already experienced the 'side-effect' before treatment. Another study found that pretreatment function was the strongest predictor of post-treatment function (Talcott et al., 2003). We did not find pre-treatment function to be as important and this difference is possibly due to the fact that men in our study were at least 2 , and up to 18 , years post-diagnosis while those in the other study were only 2 years after treatment; accuracy of recall may be poorer, or some side-effects may have resolved by the time of the survey, in our study. Presence of comorbidities was particularly associated with a higher risk of 'current' physical side-effects with an association evidence for four of seven physical side-effects. As (Hoffman, 2012) suggests men of older age are more likely to have comorbidities and this can affect PCa treatment tolerance and possible benefits of aggressive cancer treatment. Therefore, this finding has important implications both for treatment decision-making among men with other conditions and for follow-up services post-diagnosis.

An interesting finding was that post-biopsy complications were associated with side-effects after PCa treatment, although it is not known how severe these complications were. However this may be, as (Loeb et al., 2011) have suggested, due to the selection of patients for biopsy. These authors also suggested that individualised assessment of the risk-benefit ratio is important to determine if the potentially risky procedure of a biopsy should be performed. This is confirmed by the prospective study of (Rosario et al., 2012) who found that a significant percentage of men experience problems during or after biopsy. Our findings emphasize the potential importance of choices made long before treatment on patients' outcomes after treatment and suggest better selection of patients for biopsy might lead to improved post-treatment outcomes. However, men who have had a bad experience starting with their biopsy, could be are more likely to respond to the questionnaire. Further research is necessary to investigate the association between biopsy complications and post-treatment side-effects, taking into account the advances in biopsy surgery that have been made over the years.

The following limitations should be considered when interpreting the results. Firstly, the side-effects questions used for analyses were not formally validated against a gold standard and their psychometric properties were not examined. However, they were pretested among men with PCa so have face validity. The measures for pre- and post-treatment symptoms differed and the measure of side-effect severity did not include timing or duration. Also, if men received more than one treatment, they were included more than once. Fourthly, there were reasonable levels of missing response to the side-effects questions. These men were categorised as 'never had the side-effect' so the estimates of prevalence are likely to be conservative. In addition, a notable proportion of respondents had unknown stage and grade, even after checking medical records and were excluded from the analysis. This means that it is possible that the men of a particular stage/grade included in the analysis may not be entirely representative of all men with that stage/grade. Sixth, the study had a response rate of $54 \%$. In order to address for the excluded respondents and the difference between respondents and 
non-respondents, which is described elsewhere (Drummond et al., 2015a), analyses were weighted for age at diagnosis, jurisdiction and time since diagnosis, so that results would be representative of all PCa survivors in Ireland. However, it is possible that differences between ineligible and eligible survivors and respondents and non-respondents consisted of other variables and may have affected the outcome (Drummond et al., 2015a). Seventh, in this study men reported their pre- and post-treatment symptoms and these men were up to 18 years post-diagnosis, and it is not certain whether, or how, accuracy of recall of pre-treatment symptoms (for example) differs by time since diagnosis. In addition, clinical practice has changed over the time window during which the study participants were diagnosed and treated (e.g. advances have been made in the ways biopsies are taken) and these could have influenced the likelihood of experiencing side-effects. Lastly, the Nagelkerke $\mathrm{R}^{2}$ indicated that the models had relatively low predictive value, suggesting that there are other important factors associated with treatment-related side-effects which have not been identified.

In conclusion, in this large, population-based study, treatment is the most important factor associated with post-treatment side-effects. After treatment, various other factors such as pre-treatment function, comorbidities and biopsy complications were strongly associated with a higher risk of side-effects. These findings may be used to better inform PCa patients and physicians about the potential sideeffects associated with specific treatments and which patients may be at risk of these, as well as informing strategies for post-treatment follow-up and monitoring. This could ultimately lead to better informed treatment decision-making and better support after treatment. 


\section{References}

CHAPPLE, A., ZIEBLAND, S., HERXHEIMER, A., MCPHERSON, A., SHEPPERD, S. \& MILLER, R. 2002. Is 'watchful waiting' a real choice for men with prostate cancer? A qualitative study. BJU Int, 90, 257-64.

CHEN, R. C., CLARK, J. A. \& TALCOTT, J. A. 2009. Individualizing Quality-of-Life Outcomes Reporting: How Localized Prostate Cancer Treatments Affect Patients With Different Levels of Baseline Urinary, Bowel, and Sexual Function. Journal of Clinical Oncology, 27, 3916-3922.

D'AMICO, A. V., WHITTINGTON, R., MALKOWICZ, S., SCHULTZ, D., BLANK, K., BRODERICK, G. A., TOMASZEWSKI, J. E., RENSHAW, A. A., KAPLAN, I., BEARD, C. J. \& WEIN, A. 1998. Blochemical outcome after radical prostatectomy, external beam radiation therapy, or interstitial radiation therapy for clinically localized prostate cancer. JAMA, 280, 969-974.

DARWISH-YASSINE, M., BERENJI, M., WING, D., COPELAND, G., DEMERS, R. Y., GARLINGHOUSE, C., FAGERLIN, A., NEWTH, G. E., NORTHOUSE, L., HOLMES-ROVNER, M., ROVNER, D., SIMS, J. \& WEI, J. T. 2014. Evaluating long-term patient-centered outcomes following prostate cancer treatment: findings from the Michigan Prostate Cancer Survivor study. J Cancer Surviv, 8, 121-30.

DRUMMOND, F. J., KINNEAR, H., DONNELLY, C., O'LEARY, E., O'BRIEN, K., BURNS, R. M., GAVIN, A. \& SHARP, L. 2015a. Establishing a population-based patient-reported outcomes study (PROMs) using national cancer registries across two jurisdictions: the Prostate Cancer Treatment, your experience (PiCTure) study. BMJ Open, 5, e006851.

DRUMMOND, F. J., KINNEAR, H., O'LEARY, E., DONNELLY, GAVIN, A. \& SHARP, L. 2015b. Long-term health-related quality of life of prostate cancer survivors varies by primary treatment. Results from the PiCTure (Prostate Cancer Treatment, your experience) study. J Cancer Surviv, 9, 361-372.

GAVIN, A. T., DRUMMOND, F. J., DONNELLY, C., O'LEARY, E., SHARP, L. \& KINNEAR, H. R. 2015. Patient-reported 'ever had' and 'current' long-term physical symptoms after prostate cancer treatments. BJU International, 116, 397-406.

HEIDENREICH, A., AUS, G., BOLLA, M., JONIAU, S., MATVEEV, V. B., SCHMID, H. P. \& ZATTONI, F. 2008. EAU Guidelines on Prostate Cancer. European Urology, 53, 68-80.

HOFFMAN, K. E. 2012. Management of older men with clinically localized prostate cancer: the significance of advanced age and comorbidity. Semin Radiat Oncol, 22, 284-94.

INTERNATIONALAGENCYFORRESEARCHONCANCER. 2012. GLOBOCAN 2012: Prostate cancer; estimated incidence, mortality and prevalence worldwide in 2012 [Online]. World health organization. Available: http://globocan.iarc.fr/Pages/fact sheets cancer.aspx [Accessed 1106-2015].

JEMAL, A., CENTER, M. M., DESANTIS, C. \& WARD, E. M. 2010. Global Patterns of Cancer Incidence and Mortality Rates and Trends. Cancer Epidemiology Biomarkers \& Prevention, 19, 18931907.

KING, M., VINEY, R., SMITH, D., HOSSAIN, I., STREET, D., SAVAGE, E., FOWLER, S., BERRY, M., STOCKLER, M. \& COZZI, P. 2012. Survival gains needed to offset persistent adverse treatment effects in localised prostate cancer. British journal of cancer, 106, 638-645.

KNIGHT, S. J., LATINI, D. M., HART, S. L., SADETSKY, N., KANE, C. J., DUCHANE, J. \& CARROLL, P. R. 2007. Education predicts quality of life among men with prostate cancer cared for in the Department of Veterans Affairs: a longitudinal quality of life analysis from CaPSURE. Cancer, 109, 1769-76.

KORFAGE, I. J., HAK, T., DE KONING, H. J. \& ESSINK-BOT, M.-L. 2006. Patients' perceptions of the side-effects of prostate cancer treatment-A qualitative interview study. Social Science \& Medicine, 63, 911-919.

LOEB, S., CARTER, H. B., BERNDT, S. I., RICKER, W. \& SCHAEFFER, E. M. 2011. Complications After Prostate Biopsy: Data From SEER-Medicare. The Journal of Urology, 186, 1830-1834. 
MILleR, D. C., SANDA, M. G., DUNN, R. L., MONTIE, J. E., PIMENTEL, H., SANDLER, H. M., MCLAUGHLIN, W. P. \& WEI, J. T. 2005. Long-Term Outcomes Among Localized Prostate Cancer Survivors: Health-Related Quality-of-Life Changes After Radical Prostatectomy, External Radiation, and Brachytherapy. Journal of Clinical Oncology, 23, 2772-2780.

MOTTET, N., BELLMUNT, J., BRIERS, E., BERGH, R. C. N. V. D., BOLLA, M., CASTEREN, N. J. V., CORNFORD, P., CULINE, S., JONIAU, S., LAM, T., MASON, M. D., MATVEEV, V., POEL, H. V. D., KWAST, T. H. V. D., ROUVIERE, O. \& WIEGEL, T. 2015. Guidelines on prostate cancer [Online]. European Association of Urology. Available: http://uroweb.org/wp-content/uploads/09Prostate-Cancer LR.pdf [Accessed June 2015].

NAM, R. K., CHEUNG, P., HERSCHORN, S., SASKIN, R., SU, J., KLOTZ, L. H., CHANG, M., KULKARNI, G. S., LEE, Y. \& KODAMA, R. T. 2014. Incidence of complications other than urinary incontinence or erectile dysfunction after radical prostatectomy or radiotherapy for prostate cancer: a population-based cohort study. The lancet oncology, 15, 223-231.

NORDSTROM, T., BRATT, O., ORTEGREN, J., ALY, M., ADOLFSSON, J. \& GRONBERG, H. 2016. A population-based study on the association between educational length, prostate-specific antigen testing and use of prostate biopsies. Scand J Urol, 50, 104-9.

POTOSKY, A. L., DAVIS, W. W., HOFFMAN, R. M., STANFORD, J. L., STEPHENSON, R. A., PENSON, D. F. \& HARLAN, L. C. 2004. Five-year outcomes after prostatectomy or radiotherapy for prostate cancer: the prostate cancer outcomes study. Journal of the National Cancer Institute, 96, 1358-1367.

ROBINSON, J. W., MORITZ, S. \& FUNG, T. 2002. Meta-analysis of rates of erectile function after treatment of localized prostate carcinoma. Int J Radiat Oncol Biol Phys, 54, 1063-8.

ROSARIO, D. J., LANE, J. A., METCALFE, C., DONOVAN, J. L., DOBLE, A., GOODWIN, L., DAVIS, M., CATTO, J. W. F., AVERY, K., NEAL, D. E. \& HAMDY, F. C. 2012. Short term outcomes of prostate biopsy in men tested for cancer by prostate specific antigen: prospective evaluation within ProtecT study. Bmj, 344, d7894.

SANDA, M. G., DUNN, R. L., MICHALSKI, J., SANDLER, H. M., NORTHOUSE, L., HEMBROFF, L., LIN, X., GREENFIELD, T. K., LITWIN, M. S. \& SAIGAL, C. S. 2008. Quality of life and satisfaction with outcome among prostate-cancer survivors. New England Journal of Medicine, 358, 12501261.

TALCOTT, J. A., MANOLA, J., CLARK, J. A., KAPLAN, I., BEARD, C. J., MITCHELL, S. P., CHEN, R. C., O'LEARY, M. P., KANTOFF, P. W. \& D'AMICO, A. V. 2003. Time course and predictors of symptoms after primary prostate cancer therapy. Journal of Clinical Oncology, 21, 39793986.

WAGNER, W., BOELLING, T., HAMBRUEGGE, C., HARTLAPP, J. \& KRUKEMEYER, M. G. 2011. Patients' Satisfaction with Different Modalities of Prostate Cancer Therapy-A Retrospective Survey among 634 Patients. Anticancer research, 31, 3903-3908.

WILT, T. J. \& AHMED, H. U. 2013. Prostate cancer screening and the management of clinically localized disease. BMJ: British Medical Journal, 346. 
Table 1: Characteristics of the survivors, overall and for early and late disease $\| \mathcal{S}$

\begin{tabular}{|c|c|c|c|}
\hline Variable & $\begin{array}{c}\text { All survey } \\
\text { participants } \\
(\mathrm{n}=3348)^{* *}\end{array}$ & $\begin{array}{l}\text { Early disease } \\
\qquad(\mathrm{n}=1700)\end{array}$ & $\begin{array}{l}\text { Late disease } \\
\quad(n=689)\end{array}$ \\
\hline \multicolumn{4}{|l|}{ J urisdiction } \\
\hline Republic of I reland & $2567(76.7)$ & $1431(84.2)$ & $407(59.0)$ \\
\hline Northern I reland & $781(23.3)$ & $269(15.8)$ & $282(41.0)$ \\
\hline \multicolumn{4}{|l|}{$\begin{array}{l}\text { Time since diagnosis at questionnaire } \\
\text { completion }\end{array}$} \\
\hline $2-4.99$ years & $1391(76.7)$ & $743(43.7)$ & $322(46.7)$ \\
\hline 5-9.99years & $781(23.3)$ & $745(43.8)$ & $274(39.8)$ \\
\hline$\geq 10$ years & $522(15.6)$ & $212(12.5)$ & $93(13.5)$ \\
\hline \multicolumn{4}{|l|}{ Age at diagnosis } \\
\hline$<59$ & $721(21.5)$ & $420(24.7)$ & $147(21.3)$ \\
\hline 60-69 & $1484(44.3)$ & $796(46.8)$ & $311(45.1)$ \\
\hline$\geq 70$ & $1143(34.1)$ & $484(28.5)$ & $232(33.6)$ \\
\hline \multicolumn{4}{|l|}{ Living alone } \\
\hline Living alone & $434(13.0)$ & $210(12.4)$ & $88(12.7)$ \\
\hline Living with others & $2863(85.5)$ & $1463(86.0)$ & $593(86.0)$ \\
\hline \multicolumn{4}{|l|}{ Education } \\
\hline Primary & $1203(35.9)$ & $542(31.9)$ & $276(40.0)$ \\
\hline Secondary & $1139(34)$ & $629(37.0)$ & $218(31.6)$ \\
\hline Tertiary or higher & $860(25.7)$ & $452(26.6)$ & $178(25.8)$ \\
\hline \multicolumn{4}{|l|}{ Pre-treatment function } \\
\hline Urinating more frequently & $1708(51.0)$ & $830(48.8)$ & $348(50.5)$ \\
\hline Pain while urinating & $256(7.7)$ & $101(5.9)$ & $56(8.1)$ \\
\hline Blood in urine & $232(6.9)$ & $91(5.4)$ & $55(8.0)$ \\
\hline Erectile dysfunction & $626(18.7)$ & $302(17.8)$ & $142(20.6)$ \\
\hline Loss of interest in sex & $496(14.8)$ & $235(13.8)$ & $118(17.2)$ \\
\hline Back pain & $498(14.9)$ & $227(13.3)$ & $134(19.4)$ \\
\hline \multicolumn{4}{|l|}{ Number of comorbidities } \\
\hline None & $1458(43.5)$ & $754(44.4)$ & $307(44.5)$ \\
\hline $1-2$ & $1682(50.2)$ & $863(50.8)$ & $324(47.0)$ \\
\hline 3 or more & $208(6.2)$ & $83(4.9)$ & $58(8.5)$ \\
\hline \multicolumn{4}{|l|}{ Biopsy complications } \\
\hline No biopsy & $367(11)$ & $139(8.2)$ & $79(11.4)$ \\
\hline Biopsy \& bleeding into bladder & $284(8.5)$ & $161(9.5)$ & $49(7.1)$ \\
\hline Biopsy \& bleeding into rectum & $203(6.1)$ & $102(6.0)$ & $36(5.5)$ \\
\hline Biopsy \& infection & $145(4.3)$ & $85(5.0)$ & $24(3.5)$ \\
\hline Biopsy \& no complications & $539(16.1)$ & $194(11.4)$ & $190(27.5)$ \\
\hline TURP & $298(8.9)$ & $120(7.1)$ & $46(6.7)$ \\
\hline \multicolumn{4}{|l|}{ Treatment* } \\
\hline Radical Prostatectomy & $842(25.1)$ & $503(29.6)$ & $181(26.3)$ \\
\hline External Beam Radiotherapy & $1930(57.6)$ & $910(53.5)$ & $484(70.3)$ \\
\hline \multicolumn{4}{|l|}{ Hormone Therapy } \\
\hline No hormone therapy & $1454(43.4)$ & $935(55.0)$ & $182(26.4)$ \\
\hline Previous hormone therapy & $888(26.5)$ & $402(23.7)$ & $246(35.6)$ \\
\hline Current hormone therapy & $632(18.9)$ & $159(9.3)$ & $214(31.0)$ \\
\hline Brachytherapy & $184(5.5)$ & $119(7.0)$ & $13(1.9)$ \\
\hline Active Surveillance/ Watchful Waiting & $165(4.9)$ & $100(5.9)$ & $6(0.8)$ \\
\hline
\end{tabular}

$\|$ Variables are weighted by age at diagnosis, jurisdiction and time since diagnosis to be representative of the entire PCa survivor population in I reland.

$\int$ Localised disease is labelled as early disease, locally advanced/advanced disease is labelled as late disease. * Patients could have had more than one treatment, so percentages for each treatment do not sum to $100 \%$ ** Includes 959 survivors not classified as having early or late disease, largely because of unknown stage or grade. 
Table 2: Multivariate analysis: factors significantly associated with current and severe side-effects in early disease $\| \int$

\begin{tabular}{|c|c|c|c|c|c|c|}
\hline \multirow[t]{2}{*}{ Side-effect } & \multicolumn{3}{|c|}{ Current side-effects } & \multicolumn{3}{|c|}{ Severe side-effects ever experienced } \\
\hline & Variable & & OR (95\% CI) & Variable & & OR (95\% Cl) \\
\hline \multirow{9}{*}{$\begin{array}{l}\text { Urinary } \\
\text { incontinence }\end{array}$} & \multirow[t]{2}{*}{ Radical prostatectomy } & No & 1.00 & \multirow[t]{2}{*}{ Radical prostatectomy } & No & 1.00 \\
\hline & & Yes & $3.03(2.28-4.03)$ & & Yes & 3.62 (2.39-5.49) \\
\hline & \multirow{3}{*}{$\begin{array}{l}\text { Comorbidities at } \\
\text { diagnosis }\end{array}$} & None & 1.00 & \multirow[t]{3}{*}{ Age at diagnosis } & $<59$ & 1.00 \\
\hline & & $1-2$ & $1.29(0.96-1.72)$ & & $60-69$ & $0.59(0.39-0.88)^{*}$ \\
\hline & & $\geq 3$ & $2.34(1.34-4.09) *$ & & $\geq 70$ & $0.68(0.38-1.20)$ \\
\hline & \multirow{2}{*}{$\begin{array}{l}\text { Active surveillance/ } \\
\text { watchful waiting }\end{array}$} & No & 1.00 & & & \\
\hline & & Yes & $0.40(0.16-0.99)$ & & & \\
\hline & \multirow{2}{*}{$\begin{array}{l}\text { Urinating more } \\
\text { frequently at diagnosis }\end{array}$} & No & 1.00 & & & \\
\hline & & Yes & $1.72(1.25-2.35)$ & & & \\
\hline \multirow[t]{21}{*}{ Loss of libido } & \multirow[t]{3}{*}{ Hormone therapy } & Never & 1.00 & \multirow[t]{3}{*}{ Hormone therapy } & Never & 1.00 \\
\hline & & Previously & $1.56(1.19-2.05)$ & & Previously & 2.17 (1.58-2.98) \\
\hline & & Currently & $2.24(1.54-3.28)$ & & Currently & $2.53(1.70-3.76)$ \\
\hline & \multirow[t]{2}{*}{ Jurisdiction } & RoI & 1.00 & \multirow[t]{2}{*}{ Jurisdiction } & RoI & 1.00 \\
\hline & & NI & $1.73(1.05-2.86)$ & & NI & $1.43(1.05-1.96)$ \\
\hline & Impotence/ erectile & No & 1.00 & Age at diagnosis & $<59$ & 1.00 \\
\hline & $\begin{array}{l}\text { dysfunction at } \\
\text { diagnosis }\end{array}$ & Yes & 1.47 (1.09-1.98) & & $60-69$ & $0.81(0.61-1.07)$ \\
\hline & Radical prostatectomy & No & 1.00 & & $\geq 70$ & $0.48(0.33-0.68)^{*}$ \\
\hline & & Yes & $1.72(1.33-2.22)$ & Radical prostatectomy & No & 1.00 \\
\hline & Active surveillance/ & No & 1.00 & & Yes & $1.51(1.11-2.05)$ \\
\hline & watchful waiting & Yes & $0.37(0.21-0.65)$ & Active surveillance/ & No & 1.00 \\
\hline & Living alone & Alone & 1.00 & watchful waiting & Yes & $0.28(0.10-0.46)$ \\
\hline & & With others & $1.56(1.13-2.11)$ & Loss of interest in sex & No & 1.00 \\
\hline & Loss of interest in sex & No & 1.00 & at diagnosis & Yes & $2.00(1.43-2.78)$ \\
\hline & at diagnosis & Yes & $1.79(1.26-2.55$ & & & \\
\hline & Comorbidities at & None & 1.00 & & & \\
\hline & diagnosis & $1-2$ & $1.13(0.91-1.40)$ & & & \\
\hline & & $\geq 3$ & $1.68(1.03-2.75)^{*}$ & & & \\
\hline & No complications after & No biopsy & 1.00 & & & \\
\hline & biopsy & Yes & $1.18(0.62-2.26)$ & & & \\
\hline & & No & $1.55(1.05-2.31)^{*}$ & & & \\
\hline Erectile & Radical prostatectomy & No & 1.00 & Radical prostatectomy & No & 1.00 \\
\hline dysfunction & & Yes & $3.30(2.56-4.23)$ & & Yes & $2.56(1.99-3.31)$ \\
\hline & Active surveillance/ & No & 1.00 & Age at diagnosis & $<59$ & 1.00 \\
\hline & watchful waiting & Yes & $0.21(0.12-0.34)$ & & $60-69$ & $1.00(0.77-1.31)$ \\
\hline & Living alone & Alone & 1.00 & & $\geq 70$ & $0.71(0.51-1.00)^{*}$ \\
\hline & & With others & 1.39 (1.01-1.91) & Education & Primary & 1.00 \\
\hline & Education & Primary & 1.00 & & Secondary & $1.33(1.02-1.72)$ \\
\hline & & Secondary & $1.67(1.29-2.16)$ & & $\geq$ Tertiary & $1.52(1.14-2.02)$ \\
\hline & & $\geq$ Tertiary & $1.67(1.25-2.24)$ & Brachytherapy & No & 1.00 \\
\hline & Erectile dysfunction at & No & 1.00 & & Yes & $0.59(0.38-0.92)$ \\
\hline & diagnosis & Yes & $1.96(1.45-2.66)$ & Active surveillance/ & No & 1.00 \\
\hline & No complications after & No biopsy & 1.00 & watchful waiting & Yes & $0.13(0.06-0.28)$ \\
\hline & biopsy & Yes & 2.35 (1.46-3.78) & Urinating more & No & 1.00 \\
\hline & & No & $1.72(1.17-2.54)$ & frequently at diagnosis & Yes & $0.78(0.62-0.98)$ \\
\hline & & & & $\begin{array}{l}\text { Impotence/ erectile } \\
\text { dysfunction at } \\
\text { diagnosis }\end{array}$ & $\begin{array}{l}\text { No } \\
\text { Yes }\end{array}$ & $\begin{array}{l}1.00 \\
1.62(1.19-2.20)\end{array}$ \\
\hline & & & & Bleeding into bladder & No biopsy & 1.00 \\
\hline & & & & after biopsy & Yes & $2.25(1.33-3.81)$ \\
\hline & & & & & No & $1.50(1.00-2.25)$ \\
\hline Bowel & External beam & No & 1.00 & External beam & No & 1.00 \\
\hline problems & radiotherapy & Yes & $3.35(2.38-4.71)$ & radiotherapy & Yes & $2.25(1.37-3.72)$ \\
\hline & Comorbidities at & None & 1.00 & Comorbidities at & None & 1.00 \\
\hline & diagnosis & $1-2$ & $1.20(0.87-1.64)$ & diagnosis & $1-2$ & $1.28(0.80-2.04)$ \\
\hline & & $\geq 3$ & $3.29(1.88-5.76)^{*}$ & & $\geq 3$ & $2.80(1.22-6.43)^{*}$ \\
\hline & Jurisdiction & RoI & 1.00 & & & \\
\hline & & $\mathrm{NI}$ & $1.72(1.21-2.45)$ & & & \\
\hline & Urinating more & No & 1.00 & & & \\
\hline & frequently at diagnosis & Yes & $1.48(1.08-2.02)$ & & & \\
\hline & Bleeding into bladder & No biopsy & 1.00 & & & \\
\hline & after biopsy & Yes & $2.32(1.08-4.96)^{*}$ & & & \\
\hline & & No & $1.42(0.70-2.89)$ & & & \\
\hline
\end{tabular}


Table 2 continued

\begin{tabular}{|c|c|c|c|c|c|c|}
\hline \multirow[t]{6}{*}{$\begin{array}{l}\text { Breast } \\
\text { changes }\end{array}$} & Hormone therapy & $\begin{array}{l}\text { Never } \\
\text { Previously } \\
\text { Currently }\end{array}$ & $\begin{array}{l}1.00 \\
3.80(1.93-7.46) \\
8.79(4.45-17.36)\end{array}$ & Hormone therapy & $\begin{array}{l}\text { Never } \\
\text { Previously } \\
\text { Currently }\end{array}$ & $\begin{array}{l}1.00 \\
4.27(1.20-15.22) \\
11.69(3.29-41.53)\end{array}$ \\
\hline & \multirow[t]{2}{*}{ Radical prostatectomy } & No & 1.00 & & & \\
\hline & & Yes & $0.33(0.13-0.85)$ & & & \\
\hline & \multirow{3}{*}{$\begin{array}{l}\text { Bleeding into rectum } \\
\text { after biopsy }\end{array}$} & No biopsy & 1.00 & & & \\
\hline & & Yes & 5.19 (1.76-15.29)* & & & \\
\hline & & No & $1.43(0.52-3.91)$ & & & \\
\hline \multirow[t]{14}{*}{ Hot flushes } & \multirow[t]{3}{*}{ Hormone therapy } & Never & 1.00 & \multirow[t]{3}{*}{ Hormone therapy } & Never & 1.00 \\
\hline & & Previously & $3.63(2.04-6.44)$ & & Previously & $12.13(6.19-23.76)$ \\
\hline & & Currently & 34.61 (19.13-62.63) & & Currently & 14.23 (7.29-27.78) \\
\hline & \multirow{3}{*}{$\begin{array}{l}\text { Time since diagnosis } \\
\text { at survey completion }\end{array}$} & $2-4.99$ & 1.00 & \multirow[t]{2}{*}{ Jurisdiction } & RoI & 1.00 \\
\hline & & $5-9.99$ & $0.60(0.39-0.92)^{*}$ & & NI & $1.81(1.18-2.76)$ \\
\hline & & $\geq 10$ & 0.77 (0.42-1.39) & \multirow[t]{2}{*}{ Radical prostatectomy } & No & 1.00 \\
\hline & \multirow{2}{*}{$\begin{array}{l}\text { External beam } \\
\text { radiotherapy }\end{array}$} & No & 1.00 & & Yes & $2.45(1.26-4.75)$ \\
\hline & & Yes & $1.93(1.15-3.22)$ & \multirow{2}{*}{$\begin{array}{l}\text { External beam } \\
\text { radiotherapy }\end{array}$} & No & 1.00 \\
\hline & \multirow[t]{6}{*}{ Education } & Primary & 1.00 & & Yes & $3.20(1.85-5.55)$ \\
\hline & & Secondary & $0.62(0.40-0.98)$ & \multirow[t]{3}{*}{ Education } & Primary & 1.00 \\
\hline & & $\geq$ Tertiary & $0.49(0.28-0.84)$ & & Secondary & $0.90(0.59-1.38)$ \\
\hline & & & & & $\geq$ Tertiary & $0.59(0.36-0.99)^{*}$ \\
\hline & & & & \multirow[t]{2}{*}{ Back pain at diagnosis } & No & 1.00 \\
\hline & & & & & Yes & $1.72(1.02-2.89)$ \\
\hline \multirow[t]{22}{*}{ Fatigue } & \multirow[t]{3}{*}{ Hormone therapy } & Never & 1.00 & \multirow[t]{3}{*}{ Hormone therapy } & Never & 1.00 \\
\hline & & Previously & $1.13(0.83-1.54)$ & & Previously & $4.60(3.06-6.91)$ \\
\hline & & Currently & $2.16(1.44-3.26)^{*}$ & & Currently & $4.91(2.87-8.40)$ \\
\hline & \multirow[t]{2}{*}{ Jurisdiction } & RoI & 1.00 & \multirow[t]{2}{*}{ Jurisdiction } & RoI & 1.00 \\
\hline & & $\mathrm{NI}$ & $2.01(1.43-2.82)$ & & NI & $1.68(1.18-2.40)$ \\
\hline & \multirow{3}{*}{$\begin{array}{l}\text { Time since diagnosis } \\
\text { at survey completion }\end{array}$} & $2-4.99$ & 1.00 & \multirow[t]{2}{*}{ Radical prostatectomy } & No & 1.00 \\
\hline & & $5-9.99$ & $0.84(0.64-1.11)$ & & Yes & $3.07(2.00-4.71)$ \\
\hline & & $\geq 10$ & $0.55(0.35-0.85)^{*}$ & \multirow{2}{*}{$\begin{array}{l}\text { External beam } \\
\text { radiotherapy }\end{array}$} & No & 1.00 \\
\hline & \multirow{2}{*}{$\begin{array}{l}\text { Urinating more } \\
\text { frequently at diagnosis }\end{array}$} & No & 1.00 & & Yes & $2.51(1.71-3.68)$ \\
\hline & & Yes & 1.45 (1.09-1.92) & \multirow{3}{*}{$\begin{array}{l}\text { Time since diagnosis } \\
\text { at survey completion }\end{array}$} & $2-4.99$ & 1.00 \\
\hline & Back pain at diagnosis & No & 1.00 & & $5-9.99$ & $1.23(0.92-1.66)$ \\
\hline & & Yes & $1.78(1.24-2.57)$ & & $\geq 10$ & $0.48(0.28-0.82)^{*}$ \\
\hline & Comorbidities at & None & 1.00 & Education & Primary & 1.00 \\
\hline & diagnosis & $1-2$ & $1.18(0.89-1.55)$ & & Secondary & $0.86(0.62-1.20)$ \\
\hline & & $\geq 3$ & $2.07(1.21-3.53)^{*}$ & & $\geq$ Tertiary & $0.58(0.39-0.85)^{*}$ \\
\hline & Brachytherapy & No & 1.00 & Back pain at diagnosis & No & 1.00 \\
\hline & & Yes & $0.46(0.24-0.89)$ & & Yes & $1.53(1.13-2.08)$ \\
\hline & Active surveillance/ & No & 1.00 & & & \\
\hline & watchful waiting & Yes & $0.16(0.05-0.46)$ & & & \\
\hline & Education & Primary & 1.00 & & & \\
\hline & & Secondary & $0.84(0.62-1.14)$ & & & \\
\hline & & $\geq$ Tertiary & $0.57(0.40-0.81)^{*}$ & & & \\
\hline
\end{tabular}

|Weighted by age at diagnosis, jurisdiction, and time since diagnosis to assure representativeness for all PCa survivors in I reland.

$\int$ Localised disease is labelled as early disease, locally advanced/advanced disease is labelled as late disease.

$* p<0.05$ 
Table 3: Multivariate analysis: factors significantly associated with current and severe side-effects in late disease $\| \mathcal{S}$

\begin{tabular}{|c|c|c|c|c|c|c|}
\hline \multirow[t]{2}{*}{ Side-effect } & \multicolumn{3}{|c|}{ Current side-effects } & \multicolumn{3}{|c|}{ Severe side-effects ever experienced } \\
\hline & Variable & & OR $(95 \% \mathrm{Cl})$ & Variable & & OR (95\% Cl) \\
\hline \multirow{5}{*}{$\begin{array}{l}\text { Urinary } \\
\text { incontinence }\end{array}$} & Radical prostatectomy & No & 1.00 & Radical prostatectomy & No & 1.00 \\
\hline & & Yes & $4.45(2.97-6.66)$ & & Yes & $4.47(2.60-7.67)$ \\
\hline & Comorbidities at & None & 1.00 & No complications after & No biopsy & 1.00 \\
\hline & diagnosis & $1-2$ & $1.17(0.77-1.79)$ & biopsy & Yes & $13.42(1.26-143.06)$ \\
\hline & & $\geq 3$ & $2.27(1.16-4.44)^{*}$ & & No & $10.98(1.04-115.53)$ \\
\hline \multirow[t]{10}{*}{ Loss of libido } & Hormone therapy & Never & 1.00 & Hormone therapy & Never & 1.00 \\
\hline & & Previously & $1.71(1.09-2.68)$ & & Previously & 1.71 (1.09-2.69) \\
\hline & & Currently & $3.06(2.00-4.70)$ & & Currently & 2.33 (1.50-3.63) \\
\hline & Jurisdiction & RoI & 1.00 & Jurisdiction & RoI & 1.00 \\
\hline & & NI & $1.53(1.08-2.17)$ & & NI & $2.02(1.42-2.87)$ \\
\hline & Impotence/ erectile & No & 1.00 & Age at diagnosis & $<59$ & 1.00 \\
\hline & $\begin{array}{l}\text { dysfunction at } \\
\text { diagnosis }\end{array}$ & Yes & $2.02(1.36-3.01)$ & & $60-69$ & $0.83(0.55-1.26)$ \\
\hline & Bleeding into rectum & No biopsy & 1.00 & & $\geq 70$ & $0.34(0.21-0.53)^{*}$ \\
\hline & after biopsy & Yes & $2.48(1.06-5.83)$ & Impotence/ erectile & No & 1.00 \\
\hline & & No & $1.63(1.01-2.65)$ & $\begin{array}{l}\text { dysfunction at } \\
\text { diagnosis }\end{array}$ & Yes & $1.97(1.36-2.84)$ \\
\hline \multirow{17}{*}{$\begin{array}{l}\text { Erectile } \\
\text { Dysfunction }\end{array}$} & Radical prostatectomy & No & 1.00 & Radical prostatectomy & No & 1.00 \\
\hline & & Yes & $1.89(1.18-3.04)$ & & Yes & $3.70(2.15-6.36)$ \\
\hline & Active surveillance/ & No & 1.00 & Age at diagnosis & $<59$ & 1.00 \\
\hline & watchful waiting & Yes & $0.03(0.00-0.62)$ & & $60-69$ & $1.11(0.72-1.72)$ \\
\hline & Living alone & Alone & 1.00 & & $\geq 70$ & $0.48(0.30-0.77)^{*}$ \\
\hline & & With others & $1.63(1.01-2.63)$ & Education & Primary & 1.00 \\
\hline & Education & Primary & 1.00 & & Secondary & $1.67(1.12-2.48)$ \\
\hline & & Secondary & $1.57(1.04-2.36)$ & & $\geq$ Tertiary & 2.31 (1.52-3.49) \\
\hline & & $\geq$ Tertiary & 1.99 (1.29-3.09) & Hormone therapy & Never & 1.00 \\
\hline & Erectile dysfunction at & No & 1.00 & & Previously & $1.81(1.02-3.20)^{*}$ \\
\hline & diagnosis & Yes & $1.87(1.19-2.96)$ & & Currently & $1.38(0.80-2.37)$ \\
\hline & No complications after & No biopsy & 1.00 & Jurisdiction & RoI & 1.00 \\
\hline & biopsy & Yes & $2.07(1.17-3.66)$ & & NI & $1.81(1.26-2.60)$ \\
\hline & & No & $1.87(1.10-3.18)$ & Living alone & Alone & 1.00 \\
\hline & Age at diagnosis & $<59$ & 1.00 & & With others & $1.66(1.01-2.71)$ \\
\hline & & $60-69$ & 0.99 (0.61-1.60) & & & \\
\hline & & $\geq 70$ & $0.50(0.30-0.83)^{*}$ & & & \\
\hline \multirow{8}{*}{$\begin{array}{l}\text { Bowel } \\
\text { problems }\end{array}$} & External beam & No & 1.00 & External beam & No & 1.00 \\
\hline & radiotherapy & Yes & $2.66(1.50-4.73)$ & radiotherapy & Yes & $5.46(2.09-14.32)$ \\
\hline & Comorbidities at & None & 1.00 & Comorbidities at & None & 1.00 \\
\hline & diagnosis & $1-2$ & $2.07(1.31-3.26)$ & diagnosis & $1-2$ & 2.37 (1.22-4.63) \\
\hline & & $\geq 3$ & 3.84 (1.96-7.52) & & $\geq 3$ & $7.31(3.15-16.92)$ \\
\hline & Hormone therapy & Never & 1.00 & & & \\
\hline & & Previously & $1.53(1.11-3.78)$ & & & \\
\hline & & Currently & $2.05(1.31-3.26)$ & & & \\
\hline \multirow{10}{*}{$\begin{array}{l}\text { Breast } \\
\text { changes }\end{array}$} & Hormone therapy & Never & 1.00 & Radical prostatectomy & No & 1.00 \\
\hline & & Previously & $2.84(1.24-6.50)$ & & Yes & $0.11(0.05-0.24)$ \\
\hline & & Currently & $5.14(2.30-11.52)$ & Age at diagnosis & $<59$ & 1.00 \\
\hline & External beam & No & 1.00 & & $60-69$ & $0.41(0.27-0.63)$ \\
\hline & radiotherapy & Yes & $2.06(1.13-3.78)$ & & $\geq 70$ & $0.14(0.05-0.43)$ \\
\hline & Jurisdiction & RoI & 1.00 & & & \\
\hline & & NI & $2.17(1.38-3.42)$ & & & \\
\hline & Infection after biopsy & No biopsy & 1.00 & & & \\
\hline & & Yes & $3.17(1.06-9.49)^{*}$ & & & \\
\hline & & No & $1.48(0.70-3.12)$ & & & \\
\hline \multirow[t]{11}{*}{ Hot flushes } & Hormone therapy & Never & 1.00 & Hormone therapy & Never & 1.00 \\
\hline & & Previously & $2.49(1.26-4.93)$ & & Previously & $12.90(4.71-35.30)$ \\
\hline & & Currently & $12.23(6.30-23.76)$ & & Currently & $10.93(4.06-29.42)$ \\
\hline & Time since diagnosis & $2-4.99$ & 1.00 & Jurisdiction & RoI & 1.00 \\
\hline & at survey completion & $5-9.99$ & $0.57(0.37-0.86)$ & & NI & 1.99 (1.33-2.99) \\
\hline & & $\geq 10$ & $0.45(0.24-0.84)$ & Age at diagnosis & $<59$ & 1.00 \\
\hline & Jurisdiction & RoI & 1.00 & & $60-69$ & $0.49(0.27-0.75)$ \\
\hline & & NI & $2.82(1.88-4.22)$ & & $\geq 70$ & $0.43(0.25-0.74)$ \\
\hline & Age at diagnosis & $<59$ & 1.00 & Bleeding into rectum & No biopsy & 1.00 \\
\hline & & $60-69$ & $0.45(0.27-0.76)^{*}$ & after biopsy & Yes & $3.02(1.16-7.88)^{*}$ \\
\hline & & $\geq 70$ & $0.60(0.35-1.03)$ & & No & $1.31(0.64-2.69)$ \\
\hline
\end{tabular}




\begin{tabular}{|c|c|c|c|c|c|c|}
\hline \multicolumn{6}{|l|}{ Fatigue } & 1.00 \\
\hline & & Previously & $1.07(0.62-1.84)$ & & Previously & 3.28 (1.95-5.52) \\
\hline & & Currently & $2.33(1.36-3.99)^{*}$ & & Currently & $3.06(1.81-5.18)$ \\
\hline & Jurisdiction & RoI & 1.00 & Jurisdiction & RoI & 1.00 \\
\hline & & NI & $1.99(1.36-2.92)$ & & NI & $1.60(1.11-2.31)$ \\
\hline & Time since diagnosis & $2-4.99$ & 1.00 & Age at diagnosis & $<59$ & 1.00 \\
\hline & at survey completion & $5-9.99$ & $0.65(0.44-0.95)$ & & $60-69$ & $0.46(0.30-0.73)$ \\
\hline & & $\geq 10$ & $0.52(0.29-0.92)$ & & $\geq 70$ & $0.33(0.20-0.55)$ \\
\hline & Urinating more & No & 1.00 & Comorbidities at & None & 1.00 \\
\hline & frequently at diagnosis & Yes & $1.66(1.14-2.40)$ & diagnosis & $1-2$ & $1.23(0.85-1.79)$ \\
\hline & Back pain at diagnosis & No & 1.00 & & $\geq 3$ & $1.93(1.02-6.36)^{*}$ \\
\hline & & Yes & $1.76(1.16-2.67)$ & Bleeding into rectum & No biopsy & 1.00 \\
\hline & Comorbidities & None & 1.00 & after biopsy & Yes & $2.67(1.12-6.36)^{*}$ \\
\hline & & $1-2$ & $1.52(1.04-2.22)^{*}$ & & No & $1.00(0.55-1.82)$ \\
\hline & & $\geq 3$ & $1.68(0.88-3.23)$ & & & \\
\hline & Age at diagnosis & $<59$ & 1.00 & & & \\
\hline & & $60-69$ & $0.44(0.28-0.69)$ & & & \\
\hline & & $\geq 70$ & $0.31(0.19-0.52)$ & & & \\
\hline
\end{tabular}

||Weighted by age at diagnosis, jurisdiction, and time since diagnosis to assure representativeness for all PCa survivors in I reland.

$\int$ Localised disease is labelled as early disease, locally advanced/advanced disease is labelled as late disease. $* p<0.05$ 
Figure 1a: 'Current' side-effects in early and late disease (\%)

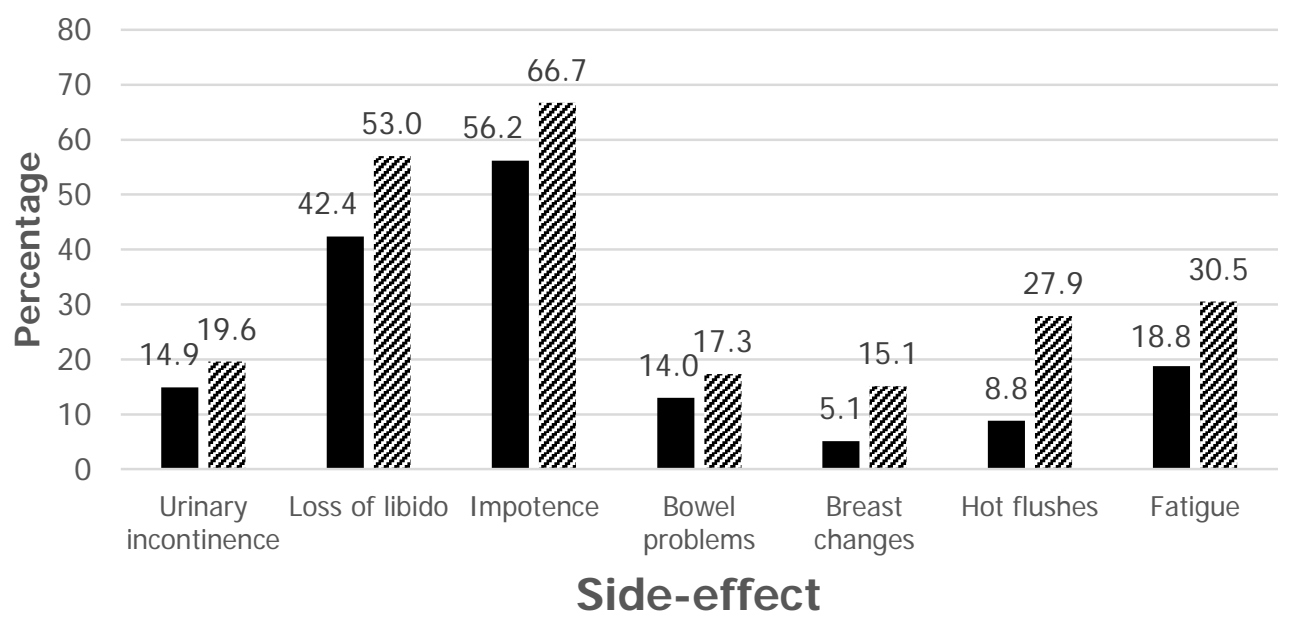

- Early $\approx$ Late 
Figure 1b: 'Severe side-effects ever experienced' in early and late disease (\%)

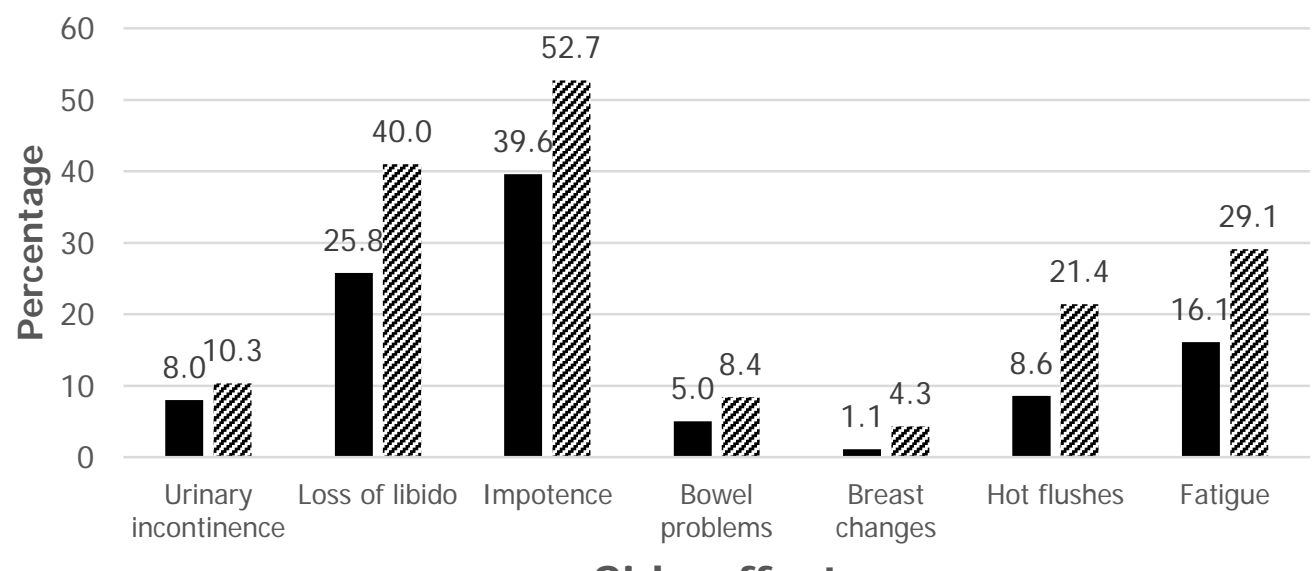

Side-effect

- Early $\approx$ Late 